\title{
23- Ivo Andriç’in “Drina Köprüsü”nde Türk kültüründen izler ve Türk tipi
}

\section{Dursun ŞAHİN 1}

\section{Julide ALACA²}

\begin{abstract}
APA: Şahin, D. \& Alaca, J. (2022). Ivo Andriç’in “Drina Köprüsü”nde Türk kültüründen izler ve Türk tipi. RumeliDE Dil ve Edebiyat Araştırmaları Dergisi, (26), 405-418. DOI: 10.2900o/rumelide.1073943.
\end{abstract}

\section{$\ddot{\mathbf{O z}}$}

Edebiyat eserleri, anlattıkları döneme ayna tutma özelliğine sahiptir. Bazı eserler de sadece ortaya çıktıkları toplumun aynası olmakla kalmamışlar, binlerce kilometre uzaklıktaki toplumlardan da izler taşımışlardır. Nobel ödüllü yazar İvo Andriç’in 1945’te yayımlanan Drina Köprüsü adlı eseri de Drina Köprüsü etrafında yüzlerce yıllık bir zaman dilimini ele almıştır. Yazar, eserinde bölgenin çok uluslu yapısı içinde köprünün yapımından 190o'lü yılların ortalarına kadar geçen sürede yaşanan olaylara yer verir. Olayların merkezinde Sokullu Mehmet Paşa ve Drina Köprüsü vardır. Onun çocukken İstanbul'a götürülüşü, sadrazam olarak geri gelişi ve Bosna-Hersek’te Drina nehri üzerine bir köprü yaptırmak istemesi ve bu süreçte yaşananlar anlatılır. Yazar, anlatımını köprünün bulunduğu yörenin coğrafyasıyla, köprü için söylenenlerle, köprü hakkındaki efsanelerle zenginleştirmiştir. Sokullu Mehmet Paşa'nın Osmanlı İmparatorluğu'nda sadrazam oluşu, bölgede yaşayan Türkler, anlatıcının eserde Türklerle ilgili pek çok yargıya, tipe yer vermesinin önünü açmıştır. Doküman inceleme yöntemiyle oluşturulan bu çalışmada, anlatıcının, yargılarında Türk kültüründen nasıl bahsettiğini, nasıl bir Türk tipine yer verdiğini ortaya çıkarmak amaçlanmıştır. Böylece hümanist kimliğiyle, farklı din ve ırklara ayrım yapmayan yaklaşımıyla bilinen yazarın, kozmopolit bir bölgede kişilere yaklaşımı Türk kültürü ve tipi özelinde tespit edilmeye çalışılmıştır. Çalışmada, kültür, Türk kültürü, edebi ürünlerde tipler ve Türk tipi üzerine genel bir giriş yapıldıktan sonra içerik analiziyle Türk kültürüne ait ögeler tespit edilerek değerlendirilmiştir.

Anahtar kelimeler: İvo Andriç, Drina Köprüsü, Türk, kültür, tip

\section{Traces of Turkish culture and Turkish character in "the Bridge on the Drina" by Ivo Andrić}

\begin{abstract}
Literary works have the feature of holding a mirror to the period they tell. Some works have not only been the mirror of the society in which they emerged, but have also carried traces of societies thousands of kilometers away. Nobel Prize-winning writer Ivo Andric's work called The Bridge on the Drina, published in 1945, also deals with a period of hundreds of years around the Drina Bridge. In his work, the author gives place to the events that took place in the multinational structure of the region from the construction of the bridge to the middle of the 1900s. At the center of the events are Sokullu Mehmet Pasha and the Drina Bridge. It tells about his being taken to Istanbul as a child, his return as grand vizier and desire to build a bridge over the Drina river in Bosnia-Herzegovina and
\end{abstract}

Dr. Öğr. Üyesi, Giresun Üniversitesi, Eğitim Fakültesi, Türkçe ve Sosyal Bilimler Eğitimi Bölümü (Giresun, Türkiye), dursunsahin@gmail.com, ORCID ID: 000o-0001-6932-9486 [Araștırma Makalesi, Makale kayıt tarihi: 24.01.2022-kabul tarihi: 20.01.2022; DOI: 10.29000/rumelide.1073943] YL Öğrencisi, Giresun Üniversitesi, Sosyal Bilimler Enstitüsü, Türkçe ve Sosyal Bilimler Eğitimi ABD (Giresun, Türkiye), alacajulide@gmail.com, ORCID ID: 0000-0003-0088-8137

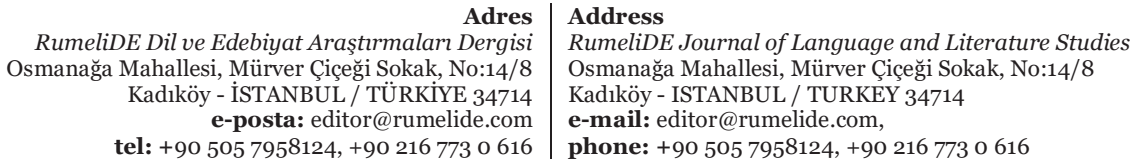


what happened in this process. The author enriched his narrative with the geography of the region where the bridge is located, what was said about the bridge, and legends about the bridge. The fact that Sokullu Mehmet Pasha was the grand vizier in the Ottoman Empire, the Turks living in the region, paved the way for the narrator to include many judgments and types about Turks in the work. In this study, which was created by document analysis method, it was aimed to reveal how the narrator talks about Turkish culture in his judgments and what kind of Turkish type he includes. Thus, the approach of the author, who is known for his humanist identity and his approach that does not discriminate against different religions and races, to people in a cosmopolitan region has been tried to be determined in the context of Turkish culture and type. In the study, after a general introduction on culture, Turkish culture, types in literary products and Turkish person type, elements of Turkish culture were determined and evaluated with content analysis.

Keywords: Ivo Andric, The Bridge on the Drina, Turkish, culture, type

\section{Giriş}

Kültür en geniş etnografik anlamıyla alındığında, insanoğlunun toplumun bir mensubu olarak edindiği bilgi, inanç, sanat, töre, yasa, görenek ve diğer tüm yetenekler ile alışkanlıkların oluşturduğu karmaşık bir toplamdır (Tylor, 1871, s. 91). Meriç de kültüre “Az veya çok kalıplaşan düşünüş, duyuş ve davranış tarzları; bu bütünü birçok insan öğrenir ve bölüşür. Böylece kültür, belli kişileri hem objektif hem de sembolik olarak başkalarından ayrı bir topluluk haline getirir.” tarifini teklif eder (Meriç, 2017, s. 67). Kültür, toplumların görüş birliktelikleri etrafında ürettikleri düşünceler, inançlar, yöntemler, yemekler, kıyafetler, mimari yapılar, sanatsal ürünler çerçevesi dâhilinde insanların yaşamlarını biçimlendirdiği esnek bir bütünü ifade eden ve soyutlanabilen kurallar sistemidir.

Gökalp (1969, s. 84) kültür kavramını hars ve tehzib olarak iki farklı koldan ele almaktadır. Hars olarak ifade ettiği durum halk kültürünü yansıtmaktadır. Toplumun dili, dini, ahlâkı, edebiyatı, örfleri, adetleri, görenekleri, estetik ürünleri hars içinde toplanmaktadır. Tehzib ise yalnız yüksek bir tahsil görmüş, yüksek bir terbiye ile yetişmiş hakiki münevverlere mahsustur. Hars milli bir duruşu sergilerken tehzibin milletlerarası bir ekseni ortaya koyduğu anlaşılmaktadır. Tehzib aydın kişilerin küreselleşme ideolojisi içerisinde milli kültürüne yabancılaşmasını önlemekte ve münevverlerin milletlerarası değerlerden süzdüklerini milli değerlerle sentezleyerek yeni boyutların meydana gelmesini sağlamaktadır.

Kültürün sınırlandırılamayan bir çizgiye sahip olması, kullanıldığı farklı alanlarda yeni özellikleri bünyesine eklemesi ve sahip olduğu işlevlerin değişimlere uyum sağlayan bir yapıda bulunması onu sonsuz bir tanımlama içerisine sokmaktadır. Güvenç (1979) de ebedî tanımlar perspektifindeki kültürün belli bir duruma ağırlık verilerek yapılan betimlemelerini dokuz başlıkta toplamaktadır; Sosyal Miras ve Gelenek Birliği Olarak Kültür, Hayat Yolu ya da Biçimi Olarak Kültür, İdealler, Değerler ve Davranışlar Olarak Kültür, Çevreye Uyum Olarak Kültür, Geniş Anlamda Eğitim Olarak Kültür, Bireysel Psikoloji Olarak Kültür, Oluşumu ve Kökeni Yönünden Kültür, Düşünüş Olarak Kültür, Simge (Sembol) Olarak Kültür (Güvenç, 1979, s. 101-102).

Şimşek ve arkadaşları (2011) kültürün çeşitlerini yaygınlık derecesine göre kültür; alt ve genel kültür, ögelerinin birleşimine göre kültür; maddi ve manevi kültür, öğrenilme zamanına göre kültür; sonradan öğrenilen, birlikte oluşan ve önceden oluşan kültür, karşı kültür ve diğer kültürler olarak sıralamaktadır.

\footnotetext{
Adres $\mid$ Address

RumeliDE Dil ve Edebiyat Araşttrmaları Dergisi Osmanağa Mahallesi, Mürver Çiçeği Sokak, No:14/8 Kadıköy - İSTANBUL / TÜRKIYE 34714 e-posta: editor@rumelide.com

RumeliDE Journal of Language and Literature Studies Osmanağa Mahallesi, Mürver Çiçeği Sokak, No:14/8 Kadıköy - ISTANBUL / TURKEY 34714

e-mail: editor@rumelide.com tel: +90 5057958124, +90 2167730616 phone: +90 5057958124, +90 2167730616
} 


\section{Türk kültürü}

Bir kültürün var olması için gereken toplu yaşam, ortak görüş birliği, belirlenen ilkeler etrafında hayatını biçimlendirme özellikleri, Çin kaynaklarında Şyungnu olarak adlandırılan, Türk tarih yazımında ise Büyük Hun İmparatorluğu denilen bozkırın ilk imparatorluğunda görülür (Ögel, 1948, s. 265). Türk kültürü devlet oluşumundan önce atlı göçebe yaşam tarzında da belirli bir kültürel yönelim ortaya koyar. Türklerin tarih öncesi dönemine ait yazılı boyutta yeterli kaynak bulunmadığından kültürel incelemeler, Türk toplumunun yerleşik yaşama geçerek yazıyı etkin bir şekilde kullanması ile başlar.

Türk adını devlet ismi içinde kullanarak kültürel görünümünü doğrudan yansıtan ilk devlet Göktürklerdir. Göktürkler, Türk kültürüne dair en değerli yapıt olan Orhun Kitabelerini meydana getirerek Türklerin medeniyet sahasında yer sahibi olmasında önemli bir pay sahibi olur. Türk adının, Türk milletinin isminin geçtiği ilk Türkçe metin... İlk Türk tarihi... Taşlar üzerine yazılmış tarih... Türk devlet adamlarının millete hesap vermesi, milletle hesaplaşması... (Ergin, 2016, s. 15). İlk Türk devletlerini oluşturan Büyük Hun İmparatorluğu, Göktürkler, Avrupa Hun İmparatorluğu, Uygurlar gibi toplumlar küçük farklılıklar dışında ortak bir kültürün etrafında varlıklarını sürdürür.

Türklerin en eski dinleri Gök Tanrı dinidir. Gök Tanrı dini tek tanrılı bir dini temsil eder, tanrı sonsuzluk içinde algılanır ve Türk dini içerisinde herhangi bir putlaştırma varlığı yer almaz. Hükümdar dinin verdiği kutsallıkla beraber devlet yönetimini elinde tutar. Türk toplumu da hükümdara yönetme yetkisinin tanrı tarafından verildiğine inanarak ona büyük bir bağlılık duyar. Gök Tengri her şeyden önce bir imparatorluk tanrısıdır. Hükümdar onun tarafından gönderilen, onun benzeri veya gölgesidir. Onun yeryüzündeki temsilcisidir (Roux, 2002, s. 115).

Türk kültürü, İslamiyet’in kabulü ile birlikte yeni bir boyut kazanır. Asya'nın bozkırlarında inşa edilen Türk kültürü İslam dini ile kendini yeniden biçimlendirir. Biçimlendirmeyle birlikte Türkler ana kültür dairesinden ayrılmamak için İslamiyet üzerinde yeni yorumlamalar meydana getirir. Türklerin ana kültür merkezlerinden ayrılmayarak İslamiyet çerçevesinde inşa ettikleri Türk kültürü Oğuz Boyları arasında kendini gösterir. XII. ve XIV. yüzyıllar arasında Anadolu'da yurt edinmiş olan Oğuz Türkleri Asya'dan getirdikleri kültür tohumunu Anadolu topraklarma ekerek onu Türk İslam kültürü ekseninde büyütmüşlerdir. Sümer (1972) Oğuzların Anadolu'ya geldiklerinde maddi ve manevi harsları ile birlikte geldiklerini ve Oğuz Türkçesinin Anadolu ve İstanbul'a varmadan önce Türkistan'da bugün var olan mahiyetini içerip orada da Türk lehçelerinin en güzeli olarak nitelendirildiğini dile getirir.

Hoca Ahmet Yesevi, Yunus Emre, Hacı Bektaşi Veli, Pir Sultan Abdal, Sarı Saltuk gibi isimler İslamiyet’in Türk kültürü içinde yeni bir perspektif kazanmasını sağlar. Türk İslam kültürünün temelini oluşturan bu mutasavvıflar, Balkanlarda güçlü bir Osmanlı Devleti’nin kurulmasında önemli katkılar sağlar. Kolonizatör Türkler olarak adlandırılan bu mutasavvıflar, Balkan coğrafyasında -Drina Köprüsü romanında da örnekleri görülen- hoşgörü, adalet, eşitlik değerlerini temsil ederek Türklerin sahip olduğu nitelikleri yansıtır. Osmanlı fetihlerinin Balkanlarda bu denli hızlı yayılmasının sebepleri arasında, Türkistan'da doğan, Anadolu'da olgunlaşan ve gelişen tasavvufi düşüncenin temsilcileri olan tarikat şeyhleri ve halkla daha yakın temasta bulunan dervişlerin faaliyetleri gösterilebilir. (Barkan, 2002, s. 136).

Türk kültürünün temel eksenini oluşturan yapıtaşlarına zaman değiştikçe farklı unsurların da katılmaya başladığı görülür. Yeni oluşumlar, kültürel belleği temel gövdesinden uzaklaştırarak kendi merkezi etrafında şekillendirmeye çalışır. Türk kültürünün ana kültürel belleğinde sapmaların ortaya çıması

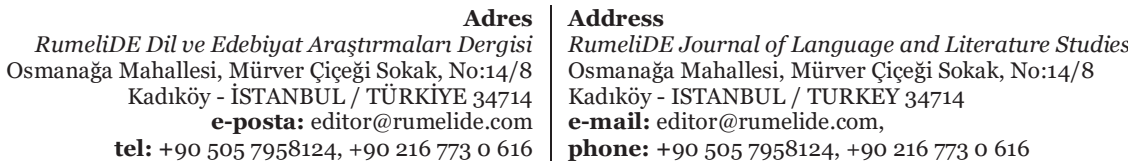


Osmanlı'nın 1453 yllında İstanbul'u fethi ile birlikte Doğu Roma mirası üzerine yerleşmesiyle başlar. Osmanlı elde ettiği bu mirastan doğrudan veya dolaylı olarak etkilenme sürecine girer. İstanbul'un fethiyle Fatih'in üçüncü bir geleneği benimsediği görülür. Fatih'in İstanbul'u aldıktan sonra kendisini Roma İmparatorluğu’nun tek varisi sayması, üçüncü geleneğin ifadesidir (İnalcık, 2009, s. 111).

Osmanlı Devleti Fatih Sultan Mehmet dönemi ile birlikte merkezi hiyerarşik bir sistem içine girmeye başlar. Osmanlı'nın benimsediği merkezileşmiş hiyerarşik yönetim sistemi o zamana kadar var olan hiçbir Türk devletinde görülmez. Osmanlı’nın içinde bulunan değerleri tekleştirip kocaman tek bir kubbe altında toplamaya çalışması ana kültürü ile çatışmalar yaşamasına sebebiyet verir. Osmanlı topraklarının her yerinde merkeze bağlı örgütlenme inşa etme amacı, onu kuruluşunda en büyük destekçisi olan Oğuz’un diğer boylarının temsilcisi olan Türkmenlerle bir mücadele içine sokar. Osmanlı vergilendirme stratejisinin göçebe hiçbir topluluk istememesi Türkmenlerin Asya'dan Anadolu topraklarına taşıdıkları Türk kültürünün zayıflamasına yol açar. Osmanlı merkezi bürokrasisi, Türkmenlerin atadan gelen hane birlikteliklerini bozup tek haneye indirerek onları ortadan kaldırır. İnalcık (2009) Fatih'in, bütün devlet yetkilerini kendinde toplamak ve imparatorluğu salt bir biçimde merkezden idare eden bir hükümdar görünümü ortaya koymak için mutlakıyetine karşı çıkan ve çlkabilecek tüm unsurları ortadan kaldırdığını veya değiştirdiğini ifade eder.

Fatih Sultan Mehmet'in merkeziyetçiliği kuvvetlendirmek için aldığı tedbirlerden biri de devleti yönetecek üst seviyedeki yöneticileri devşirmelerden seçmesi, Müslüman ve Türk asıllı olanları bu makamlardan uzaklaştırmasıdır (Demir, 2019, s. 20). 15. yüzyılın ortalarından başlayıp 18. yüzyılın başlarına kadar uygulanan devşirme sisteminde Balkanlarda yaşayan Hristiyanlardan devşirme yapılmakla birlikte 15. yüzyllın sonlarından itibaren Anadolu'daki Hristiyanlardan ve 16. yüzyılda ise bütün imparatorluk coğrafyasında yaşayan Hristiyanlardan devşirme yapılmaya başlanmıştır (Demir, 2019, s. 22).

Devşirilecek çocuklar fiziksel, ruhsal, bilişsel yönlerden birçok denetime tabi tutularak seçilmişlerdir. Beden yapısında bozukluk, anormallik bulunan, çok uzun boylu veya çok kısa boylular, köse, kel, doğuştan sünnetli olanlar devşirme alınmamış, orta boylular, vücudu uyumlu olan uzun boylular tercih edilmişlerdir. Devşirilecek çocuklar zekâ testine de tabi tutulmuşlardır. Devşirme sistemiyle 1519 yllında henüz çocuk yaştayken Edirne Sarayına getirilenlerden biri olan Sokullu Mehmet Paşa da zekâ testinden geçirilmiş, bir tabak çorbanın başına oturtulmuş ve ellerine ağıza götürülemeyecek kadar uzun kaşıklar verilmiştir. Sokullu, elindeki kaşıkla karşıdaki çocuğa çorba yedirmiş, karşıdaki çocuk da Sokullu'ya çorba yedirmiştir. Böylece her ikisi de zekâ testinden başarıyla geçmişlerdir. Testle çocukların bencil olup olmadığı, yardımlaşma niteliğine sahip olup olmadığı da tespit edilmiştir (Demir, 2019, s. 23).

Devşirilerek sadrazamlığa kadar yükselmiş olan Sokullu Mehmet Paşa, kültürel mirasa tarihi eserlerle katkılar sağlamış bir devlet adamıdır. Lüleburgaz Deresi üzerinde Mimar Koca Sinan’a yaptırdığı Lüleburgaz Köprüsü ve Lüleburgaz Sokullu Mehmet Paşa Külliyesi, bu eserlere örnek olarak gösterilebilir. Sadrazamlığı döneminde 1578'de Belgrad'a Sokollu Mehmed Paşa Çeşmesini yaptıran Sokullu, 1571 ile 1577 yılları arasında memleketi olan Sokol köyünün yakınına Bosna Hersek ve civarı Avrupa'daki köprü mimarisinin en güzel örneklerinden biri olan Drina Köprüsünü yaptırır. Köprü, Bosna ile İstanbul arasında yer alan anayol üzerinde inşa edilmiş olup etrafındaki köy ve şehirlerin gelişmesinde önemli bir rol üstlenmiştir.

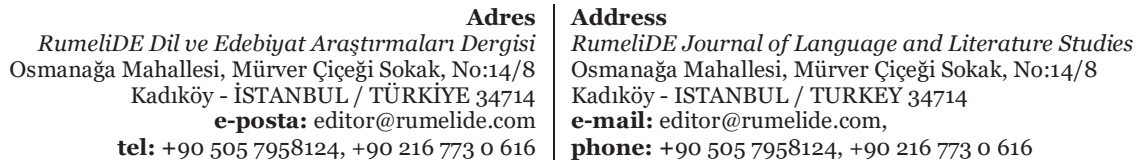




\section{Türk tipi}

Türklerin, Nuh Peygamberin oğullarından Yasef in soyundan geldikleri iddiasını dile getiren; dilleri, soy özellikleri, gelenek ve görenekleriyle, öteki uluslardan çok değişik ayrıcalıklar gösterdiklerini belirten Çağatay, Türk tipini şöyle tarif eder (Çă̆atay, 1996, s. 509):

"Türklerin en çarpıcı özellikleri: soylu, merhametli, hoşgörülü, yardım ve konuksever olmalarıdır. Onlar, kadına, yaşlıya ve çocuğa karşı son derece sevgi ve saygı beslerler. Başka uluslarla ilişkilerinde çıkan sorunlara anlaşma ile çözüm yolu aramayı yeğlerler. Bulgarların Balkan Savaşlarında, Ermenilerin Doğu Anadolu'da, Yunanlıların Balkan Savaşlarında ve Batı Anadolu'yu işgallerinde, korumasız kadınlara, yaşlılara ve çocuklara yaptıkları gibi ırza, cana, mala acımasızca saldırmalar, Türklerin hiç yapmadıkları bir şeydir. Zaten soylu bir millet bunları yapmaz. Bunun son kanıtı bu soysuzca davranışlarından sonra, Ulu Önder M. K. Atatürk'ün Anadolu'dan kovduğu o düşmanlara, öç alma duygusuyla onların yaptıklarının hiçbiri yapılmadı. M. Kemal Paşa "Yurtta barıș, cihanda barış" ilkesini benimsedi ve hep ona bağlı kaldı."

Tipleri sosyal bakımdan manalı bulan ve tiplerle içinde doğdukları toplum arasında yakın bir münasebet olduğunu belirten Kaplan (1991), “alp tipi” ve "gazi tipi” gibi birbirinin devamı gibi görünen ama din unsuru nedeniyle aralarında ciddi farklar bulunduğunu ifade ettiği iki Türk tipinden bahseder. Edebi eserlerin bir bütün olarak algılanmasına katkı sağladıkları için tipleri önemli bulan Kaplan, tipler aracllğ̆ıla, içinde meydana geldikleri toplumun sosyal şartlarını, zihniyet, örf ve adetlerini anlamanın daha kolay olacağını dile getirir (Kaplan, 1991, s. 6). Kaplan'ın çizdiği tipler, alp, gazi ve veli tipleriyle sınırlı değildir. Tanzimat sonrası aydın tipi ve esnaf ve zanaat erbabı ahi tipi de Kaplan'ın dikkat çektiği tipler arasında yer almaktadır (Kaplan, 1991, s. 7, 8). Çağatay da ahîliği, Türk yardımseverliğinin, doğruluğunun, merhametliğinin, sanat ve meslekle kucaklaşmış bir biçimi olarak görür (Çağatay, 1996, s. 516).

Türklerin iki bin ylllk tarihini anlatan Roux da ortak karakter özellikleri arasında, maddi ve manevi sağlamlık, onura verilen önem, verilen söze sadık kalmak, ihanet edenlere karşı acımasızlık, ırkçılığın olmaması. Askeri toplumsal örgütlenmenin doğurduğu gözü peklik, kendisinin ve başkalarının hayatını hiçe saymak, savaşanlar arasında dayanışma ve üste kesin itaat özelliklerini saymaktadır (Roux, 1991, s. 19).

\section{Tahkiyeli eserlerde tip}

Roman, hikâye, tiyatro, masal, biyografi, otobiyografi, hatıra gibi türler, tahkiyeli eserler olarak ifade edilmektedir. Bu eserler, olay, zaman, mekân, karakter ya da tip gibi ortak unsurlara sahiptir. Her roman en az bir başkarakter ve birçok yan karakterden meydana gelir. Karakterler çok yönlü, çok boyutludur ve karakterlerin kendine has özellikleri vardır. Tek boyutlu olan tipler ise bulunduğu toplumun izlerini ve özelliklerini taşırlar. Kendilerinde eser boyunca herhangi bir değişim ya da gelişim gözlenmez. Bu yönüyle tip, toplumsal boyutu ile ortaya çıkar ve ait olduğu sosyal durum, olay veya olgu onun üzerinden işlenir.

Edebi ürünlerde tiplerin tahlil edilmesindeki güçlüğe dikkat çeken Kara (2014), tip olarak düşünülen unsurun benzeri eserler içinde örneklerinin, tarihi bir geçmişinin ve içinden çıktığı toplum tarafından zenginleştirilerek yaşatılması gerekliliğini vurgular.

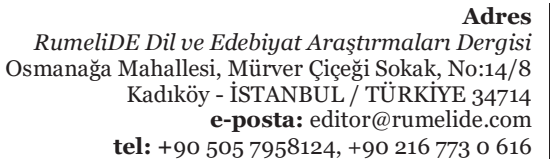

Adres /8 8 (1) tel: $+905057958124,+902167730616$
Address

RumeliDE Journal of Language and Literature Studies

Osmanağa Mahallesi, Mürver Çiçeği Sokak, No:14/8

Kadıköy - ISTANBUL / TURKEY 34714

-mail: editor@rumelide.com

phone: +90 $5057958124,+90216773$ o 616 


\section{Araștırmanın yöntemi}

Araştırma nitel araştırma yöntemleri dâhilinde bulunan doküman inceleme etrafında oluşturulmuştur. Doküman incelemesinde temel amaç; araştırılması hedeflenen olgu veya olgular hakkında bilgi içeren yazılı materyallerin analiz edilmesidir (Yıldırım ve Şimşek, 2006).

\section{Evren ve örneklem}

Araştırmanın evrenini İvo Andriç’in kaleme aldığı tüm eserler, 1945 yılında yayımlanan Drina Köprüsü adlı eseri de çalışmanın örneklemini oluşturmaktadır.

\section{Verilerin toplanması ve analizi}

Verilerin analizini gerçekleştirmede içerik analizine başvurulmuştur. Eser, araştırmacılar tarafından incelenerek eserin içeriğinde yer alan Türk kültürüne ait ögeler ve Türk tipleri tespit edilmiş, tespit edilen örnekler niteliklerine göre tasnif edilmiştir. Çalışma, Drina Köprüsü’nün Türk kültürü ögeleri ve Türk tipi açısından ilk defa incelenmesi yönüyle farklılık arz etmektedir.

\section{Bulgular}

Eserde yer alan karakterleri analiz eden Kolcu, romandaki en önemli ögenin, Drina Köprüsü olduğunu söyler (2003, s. 241). Ona göre köprü, bir simge olmanın dışında, ayrıca, Osmanlı Devleti’nin, onu yaptıran Sokullu Mehmet Paşa'nın hatırası ve kasabada yaşayan Türklerin ve diğer Müslümanların yegâne anıtıdır. Kutsallık ve simgesel anlam atfedilen bütün yapılar gibi, Drina Köprüsü de ona böyle anlamlar atfedenlerce bir dokunulmazlığa bürünür (2003, s. 241). Kolcu'nun köprüden sonra dikkat çekici bulduğu diğer karakter ise Osmanlı kültürünün ve bilincinin manevi mirasçısı olarak gördüğü Ali Hoca'dır (2003, s. 241). Ali Hoca gibi bölgede toplumların önder kabul ettiği kişilerden biri de Molla İbrahim'dir. Onunla Hıristiyan Rahip Nikola arasında çok sıkı bir dostluk vardır. Bu durum, farklı dinlere sahip insanların bir arada huzur içinde yaşamaları için örnek oluşturmuştur. Kolcu, birbirine yakın kişiler için 'hoca ile papaz gibi' ifadesinin kullanılmasını sağlayan, hoşgörüye dayalı bu dostluğun isyan ve savaş dönemlerinde sona ermek zorunda kaldığını belirtir (2003, s. 242).

Romanın çalışma konusu yapılmasının temel nedeni, eserde kimi zaman olaylar kimi zaman da kahramanlar üzerinden Türk kimliğine çok fazla gönderme yapılmasıdır. Kolcu (2003, s. 242) da bu durumu yazarın yaşadığı 19.yüzyılın sonları ve 20 yüzyılın başlarında Müslüman Boşnaklardan başka, Türklerin bugüne oranla daha yoğun ve daha hâkim bir şekilde bulunması, bizzat komşusu olan insanları, onların yaşama biçimlerini, dini ve kültürel yaşamlarını gözlemleyerek öğrenmenin dışında "Türklerin Yönetimi Altındaki Bosna-Hersek'te Kültürel Yaşam” adlı teziyle profesyonel olarak da incelemesi şeklinde ifade etmektedir.

Drina Köprüsü romanı üzerine yapılan çalışmalarda, farklı sonuçlara ulaşılmıştır. Eseri, Osmanlı algısı açısından ele alan Demir (2016, s. 470), eserde Osmanlı'nın genel olarak olumlu ve barışçıl intibalar bıraktığı sonucuna varmıştır. Eseri köprüler özelinde ele alan Bayram’ın (2014, s. 280, 281) çalışması da köprülerin birer ikona dönüştüğünü, yüzylllar içerisinde şehrin ana karakterleri olup yaşanan tarihi olaylara tanıklı etmenin ötesinde, etkin roller oynadıklarını; insanların, çocukluklarının geçtiği, aşklarını yaşadıkları, yaşama sevincini hissettikleri kadar ölümle de yüz yüze geldikleri BosnaHersek'teki köprülerin, tarih boyunca, hem ayrıştırıcı hem de birleştirici yönleriyle şehrin, kültürün önemli, vazgeçilmez yaşayan kahramanları oldukları tespitini yapmaktadır.

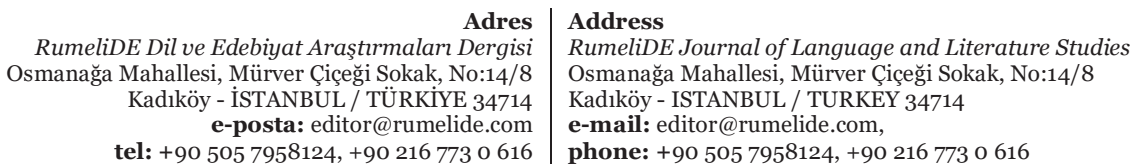


Andriç, eserinde tipleri betimlerken, genelleyici bir tutumla yaklaşmamıştır. Örneğin Türk din adamı tiplemesi olarak Molla İbrahim ve Müderris Hüseyin Efendi’yi betimlerken Molla İbrahim’i olumlu çizerken, Müderris Hüseyin Efendi’ye bakışı olumsuzdur:

Rahip Nikola'nın yanında Molla İbrahim oturuyordu. Uzun boylu, zayıf, kuru, seyrek sakallı, sarkık bıyıklı bir adamdı. Rahipten pek de genç değildi. Kalabalık bir ailesi ve babadan kalma zengin toprakları vardı. Yalnız bir çoçuğunkini andıran hareketli mavi gözleriyle öylesine zayıf, öylesine sıkılgan ve ürkekti ki, Vişegrad'ın soylu ailesinden gelme bir hocadan çok, fakir bir dervişi andirıyordu. Molla İbrahim'in bir kusuru vardı. Kekeme idi. Kasabalılar saka yollu "onunla konuşmak için insanın işi gücü olmamalı” derlerdi. Bununla birlikte Molla İbrahim cömertliğiyle, iyi yürekliliğiyle çevresinde ün salmıştı. Her halinde bir yumuşaklık, derin bir huzur ve sükûn sezilirdi. Onunla tanıştınız mı, kekemeliğini de, dış görünüşünü de unuturdunuz. Hasta, dertli ve yoksulları kendine çekerdi. En uzak köylerden bile ona akıl danışmaya gelirlerdi. Evinin önünde onu bekleyenler hiç eksik olmuyordu. Ona akıl danışmak isteyen kadınlarla erkekler sık sık yolunu keserlerdi. Kimseyi boş çevirmezdi. Öteki hocalar gibi pahalı muskalar, dualar satmazdı. Biriyle konuşacağı zaman, karşısına ilk çıkan taşa, bir gölge yere oturur, adamın yavaş sesle ona derdini anlatmasını beklerdi. Molla İbrahim büyük bir dikkat ve merhametle onu -dinler, sonunda ona birkaç tatlı söz söyler ve daima en iyi çözüm yolunu bulurdu. Bazen elini cübbesinin cebine sokar ve kimsenin görmemesine dikkat ederek adamın avucuna birkaç para sıkıştırırdı” (s. 135).

Andriç, dış görünüşünü tüm detaylarıyla anlattığı Molla İbrahim'in kekeme oluşuna rağmen etrafını nasıl etkilediğini örneklerle anlatır. Molla İbrahim, maddi, manevi sıkıntısı olan herkesin yardımcısıdır. Hurafelerle işi yoktur. İnsanların sıkıntılarına çözüm bulmaya çalışır, eğer paraya ihtiyaçları varsa "Sağ elin verdiğini, sol el görmemeli.” hadisine uygun şekilde gizlice vermektedir. Bu davranış, Türk kültüründe yardımlaşmada en çok önemsenen durumlardandır.

Romandaki bir diğer din adamı tipi olan Hüseyin Efendi, hem fizyolojik olarak hem de kişilik olarak Molla İbrahim'den oldukça farklıdır. Molla İbrahim'in aksine oldukça kiloludur. Molla İbrahim alçakgönüllü bir kişiliğe sahipken, Hüseyin Efendi, kibirli ve okumadığı kitaplarıyla ukala bir yapıya sahiptir.

"Vişegrad'ın müderrisi Hüseyin Efendi, henüz genç, oldukça kısa boylu, göbeklice bir zattı. Daima temiz ve zarif giyinirdi. Düzgün kesilmiş siyah yuvarlak bir sakalı; yuvarlak siyah gözleri, beyaz bir teni vardı. İyi bir eğitim görmüștü. Yeterince bilgiliydi. Ama kendini olduğundan da çok bilgili sanırdı. Konuşmaktan, kendini dinletmekten pek hoşlanırdı. Çok siyah kıllı, pembe tırnaklı, beyaz nazik ellerini biraz yukarı kaldırarak kelimeleri dikkatle seçerdi. Sanki bir aynanın önünde konuşuyormuş gibi davranırdı. Kasabada en çok kitabı olan o idi. Bunları çemberlerle çevrilmiş kilitli bir sandık içinde saklardı. Bunlar, hocası Arap hocadan ona miras kalmıştı. Onları yalnız tozdan ve güveden korumakla kalmaz, arada sırada da okurdu. Bu kadar çok pahalı kitabı olması, kitabın ne olduğunu bilmeyen cahillerin gözlerinde onu yükseltiyor, ona değer kazandırıyordu” (s. 136).

"Yüreği katı ve ruhu sert olanlar çabuk ihtiyarlamazlar. Kendisi hakkındaki yüksek kanaati, 20 yıl içinde daha da derinleşmişti. Lâf aramızda, bilgin diye ün almasına biraz sebep olan kitap sandığı hâlâ okunup bitirilmemiști. Kasabamızın tarihine yirmi yll içinde topu topu 4 sahifecik eklenmiști. Çünkü yaşı ilerledikçe kişiliğine ve geçmişine daha çok değer vermeye, çevresinde geçen olayları da o ölçüde önemsiz görmeye başlamıştı. Bir takım karışı el yazılarını okumaya çalışıyormuş gibi, etkileyici ciddi bir tavırla yavaş ve ağır bir sesle konuşuyordu” (s. 219).

Türklerin vatanseverliği, savaşçı kimliği, gazilik, şehitlik üzerine tavırları eserin içeriği gereği birçok yerde dile getirilmiş, bu durum zaman zaman olağanüstü imgelerle de desteklenmiştir:

"Bu sofu, akıllı, azimli ve inatçı adam, hiçbir umut olmadığı halde mücadeleden vazgeçmedi. Kasaba halkı onu uzun zaman unutmayacaktı. Dünyada insanların görevi her çeşit yıkımlarla savaşmak olduğuna kendini inandırmıştı. Bundan umudu olmasa bile yine savaşmak gerekti. Yıkılmaya yüz tutan hanın önüne oturmuş ona acıyan ve onu bu işten vazgeçirmeye çalışanlara şöyle karşllık veriyordu: - Bana hiç acımayın... Biz, sıradan insanlar, yalnız bir sefer ölürüz. Ama büyük adamlar iki sefer ölürler. Birinci sefer bu dünyayı bırakıp göçtükleri, ikinci sefer de bıraktıkları eserler, yıkılıp kaybolduğu zaman.” (s. 78).

RumeliDE Dil ve Edebiyat Araştırmaları Dergisi Osmanağa Mahallesi, Mürver Çiçeği Sokak, No:14/8 Kadıköy - İSTANBUL / TÜRKIYE 34714 e-posta: editor@rumelide.com tel: +90 $5057958124,+902167730616$
Address

RumeliDE Journal of Language and Literature Studies

Osmanağa Mahallesi, Mürver Çiçeği Sokak, No:14/8

Kadıköy - ISTANBUL / TURKEY 34714

e-mail: editor@rumelide.com

phone: +90 505 7958124, +90 2167730616 
Türk kültüründe meçhul asker, başını vermeyen şehit gibi olağanüstü kahramanlara skkça rastlanmaktadır. Bugün Anadolu'da pek çok yerde kimliği bilinmeyen askerlere ait mezarlar, türbeler yer almaktadır. Drina Köprüsü’nde yazar, Türk kültürünün bu özelliğini aynı hassasiyetle dile getirmiştir.

"Türklere gelince, onlar çok seki zamanlarda burada din uğruna şehit düşmüş bir dervişin, Şeyh Turhan'ın yatmakta olduğunu iddia ederler. $\mathrm{O}$, büyük bir kahramanmış ve küffar ordusuna karşı Drina geçidini korumuș. Bu tümseğin üstünde bir taș, bir türbe bulunmayıșının nedeni de, dervișin böyle vasiyet etmiş olmasıymış. Kimsenin onun nerede yattığını bilmemesi için, hiçbir iz bırakmadan gömülmek istemiş, çünkü küffar ordusu bir gün gelecek olursa, bu tümseğin altından kalkarak tekrar onlara yola kapatacakmış. Buna karşılık, bazen gökyüzünden bu toprak yığınına nur inermiş” (s. 20).

Yazar, Ali Hoca karakteri üzerinden Türklerin savaşçı kimliğinin yanı sıra barışçı kimliğini de dile getirmiştir. Eserde, eski huzurlu günler için yapılan dualara, halkın güven ve huzur içinde yaşaması dileklerine yer verilmiştir:

\begin{abstract}
"Sirplar, her zaman yüreklerinde yanan, sıkı sıkıya gizledikleri bu kurtuluş ateșinin bu yana, kendi tepelerine kadar uzanması için dua ediyorlardı. Müslümanlar ise, aynı ateşin sönmesi, kâfirlerin amaçlarına erişmelerine firsat vermemesi, Hak dininin sağlığı, barışı ve eski düzeni geri getirmesi için Allaha yalvarıyorlardı” (s. 89).

"Vișegrad Türklerinin coğu gibi Ali Hoca da silahlı bir direnișe karșıydı. Onun için korkaklık ve dinsizlik gibi şeyler söz konusu olamazdı. O da müftü kadar, direnişe katılanlar kadar, gelecek olan yabancı ve Hıristiyan bir idareden, onun getirebileceği her seyden tiksiniyordu. Ama Padişahın gerçekten Bosna'yı Nemse'lilere bıraktığını bilen, hemşerilerini de çok iyi tanıyan Ali Hoca, düzensiz bir halk direnişinin ancak yenilgi ile sonuçlanacağını, daha büyük bir felâkete yol açacağını düşünüyordu. Bir kere bu düşünce kafasına yerleşince onu açıkça yaydı, şiddetle savundu” (s. 122).
\end{abstract}

Akgündüz, devletin güçlü olduğu dönemlerde devşirme asıllı olanların devlete son derece sadık olduklarını, padişahın fakir Hristiyanların zeki çocuklarını alıp onları yönetici, asker haline getirdiklerini, çocuğunu devşirme olarak veren ailelerin belli başlı vergilerden muaf tutulduklarını, bu sebeple gayrimüslim Osmanlı vatandaşların çocuklarını devşirme yazdırabilmek için devşirme memuruna rüşvet verdiklerini anlatır (Akgündüz, 1999, s. 46). Andriç̧in Osmanlı İmparatorluğu'nun devşirme sistemine karşı bakışı değişkenlik göstermektedir. Kimi yerde çocukların ailelerinden koparılmalarını trajik bir biçimde gözler önüne sererken kimi zaman da devşirilen çocuğun ileride çok yüksek makamlara gelişi gururla dillendirilmektedir. Yazardaki fikir değişikliğinin nedeni, Akgündüz’ün tespitinde olduğu gibi, Osmanlı İmparatorluğu’nun gücüyle de ilişkilidir.

"Çocukları ellerinden alınan analar, babalar, kardeșler saç baș dağınık, perişan nefes nefese atların arkasından koşuyor, İslâm yapılmak, sünnet edilmek üzere yabancı diyarlara götürülen çocuklarının ardından sürükleniyorlardı. Artık onlar, dinlerini, asıllarını, yurtlarını unutmaya, ömürlerini yeniçeri ocaklarında veya Osmanlı İmparatorluğunun önemli başka işlerinde geçirmeye mahkûmdular” (s. 26).

"Bu sepetteki çocuğun ileride ne olduğunu bütün tarih kitapları anlatır. Ve dünya onu bizden de iyi bilir. Zamanla o, padişah sarayında, genç, gözü pek bir subay olarak hizmet etti, kaptan paşalığa yükseldi, padişaha damat oldu ve şöhreti cihana yayıldı. O Sokullu Mehmet Paşa ki, üç kıtada çoğu zaferle sona eren savaşlarıyla, Osmanlı İmparatorluğu'nun sınırlarını genişletti, ona içte ve dışta güven içinde bir idare sağladı" (s. 28).

Andriç, Drina Köprüsü’nde Türklerin kişilik özelliklerinden uyanık, zeki ve kurnaz oluşlarına da yer vermiş, Türklerin kandırılamayacağını vurgulamıştır:

"Türklerin zeki ve kurnaz olduklarını, böyle şeyleri yutmayacaklarını, son gününe kadar bu angaryaya katlanmalarını ve durumlarını daha feci hale sokmamalarını söylüyorlardı” (s. 37).

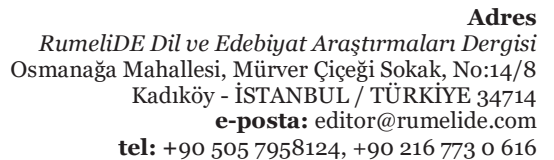

Adres RumeliDE Dil ve Edebiyat Araşttrmaları Dergisi Kadıköy - İSTANBUL / TÜRKIYE 34714 tel: $+905057958124,+902167730616$
Address

RumeliDE Journal of Language and Literature Studies

Osmanağa Mahallesi, Mürver Çiçeği Sokak, No:14/8

Kadıköy - ISTANBUL / TURKEY 34714

e-mail: editor@rumelide.com

phone: +90 5057958124, +90 2167730616 
Türklerde devletin imkanlarını kendi menfaatleri uğruna kullanmak, cezasız bırakılmamaktadır. Yazar, Türklerin hileye, yolsuzluğa geçit vermeyen kişiliklerine de yer vermiş; devlet memurlarının namussuzluk, hırsızlık yapmalarının bedelini ödemek zorunda kalışlarını Abid Ağa özelinde örneklendirmiştir:

\begin{abstract}
"İki yıl süresince, her gün iki-üç yüz kişinin bedava çalıştıklarını, on para almadıktan başka kendi hesaplarına karınlarını doyurduklarını, Sadrâzamın verdiği paraları Âbid Ağa'nın cebine attığını (cebine attığı paranın miktarını, kurușuna kadar hesaplamıșlardı), bu gibi hallerde her zaman olduğu gibi, onun da bu hileciliğini, büyük bir çalışkanlık, sertlik maskesi altında gizlediğini, zulmüyle sade Hıristiyanları değil, Müslümanları da bıktırdığını, bu mübarek hayır ișinden, bu zengin vakfiyeden sevineceklerine, tam tersine, onu yapanları da, yaptıranları da lanetle andıklarını anlatmıştı. Ömrü boyunca, memurların namussuzluğu ve hırsızlığı ile savaşmıs olan Vezir, ona ihanet eden bu hırsızı çağırtıp hemen çaldığı paraları geri vermesini söylemiş. Ve daha büyük bir cezadan kurtulmak istiyorsa, hemen pılısını pırtısını, çoluğunu çocuğunu toplayıp Anadolu'nun küçük bir kasabasına göç etmesini emretmiş." (s. 65).
\end{abstract}

Âbid Ağa gibi kendisine verilen yetkiyi kötüye kullanan bir diğer karakter de Tahir Ağa'dır. Yazar, Tahir Ağa gibilerin huzuru kaçırdıklarını, geçmişte Türklerin olduğu yerlerde her zaman huzurun egemen olduğunu anlatır:

"Türklerin zamanındaki o tatlı ve sakin yaşam yoktu ama (bu zaten imkânsızdı) yeni anlayışa göre her şey düzenleniyordu. Tam o sırada ülkede yine kargaşalıklar başladı. Kasabaya yeni askerî birlikler geldi ve Kapiya'ya tekrar nöbetçi kondu” (s. 164).

"Bana öyle geliyor ki, bu bir gâvur icadıdır! diye söze başladı. Fazla değilse bundan 30 yıl önce Travnik'te Tahir Paşa adlı bir vezir vardı. Hıristiyandan dönme, münafik, iki yüzlü bir adamdı. Müslümanlı̆̆ kabul etmekle birlikte, kalben eskiden olduğu gibi, Hıristiyan kalmıştı. Anlattıklarına göre yanında her zaman bir çan bulundurur, uşağını çağıracağı zaman papazlar gibi bu çanı çalarmış. İşte Travnik'te evlere numara koyan ilk insan bu Tahir Paşa oldu. Her evin üstüne numaralı bir tahta çaktırdı. O yüzden ona "Tahtacı" lâkabını takmışlardı. Ama halk ayaklandı, bütün bu tahtaları söküp bir araya topladı ve yaktı. Az daha kan dökülecekti. Ama bereket versin İstanbul bunu haber aldı, Tahir Paşayı geri çağırdılar. Şimdiki de ona benziyor. Nemseli'ler her şeyin, hatta yaşlarımızın bile hesabını tutmak istiyorlar" (s. 165).

Türklerin maddi unsurlara yükledikleri kültürel anlamlar, köprü özelinde de tasvir edilmiştir. Çünkü köprü hem olumlu hem olumsuz manada birçok özellik taşımaktadır. Bir dönem üzerinde hayatın canlılığının sahnelendiği, insanların uğurlandığı, ardından suların döküldüğü köprü, acılar yaşandıktan sonra da hüznün simgesi olmuştur:

"İster insan olsun, ister eșya, Saray-Bosna ve Saray-Bosna yoluyla bütün batı dünyasına yapılan her türlü taşıma işleri, o günden sonra artık Drina'nın sağ kıyısından yapılmaya başlandı. Sol kıyı ve onunla birlikte köprü de felce uğramıştı. Artık köprüden sadece sol kıyıda oturan köylülerin yük taşıyan atlarıyla, ormanlardan istasyona odun taşıyan öküz ya da at arabaları geçiyordu. Köprüden sonra Lieska tepesini geçerek Saray-Bosna'ya giden yolu, eskiden arabacıların şarkı sesleri ve hayvanların boyunlarındaki çıngırakların yankılarıyla inleyen yolu, bazı evlerle yolların son demlerini süsleyen ot ve yosunlar kaplamaya başlamıştı. Artık yolculuklarda köprü kullanılmıyor, kimse oradan uğurlanmıyor, orada vedalaşılmıyor, yolcular atlarla uğurlanmıyor ve geceleri at üstündeki yolcuların arkasindan su dökülmüyordu" (s. 230, 231).

Türk insanı, velileri üstün kuvvet ve özelliklere sahip, Allah'a yakın olan bir şahsiyet olarak görmekte ve herhangi bir konuda yardımının dokunacağına inanmaktadır. Ayrıca bu kişilerin Allah'ın sevgili kulları, keramet sahibi, alçak gönüllü, sıkıntı anında insanlara yardımcı olan, duaları geri çevrilmeyen, şefaat eden, gaybı bilen ve hastaları iyileştiren gibi özelliklerinin olduğuna da inanılmaktadır (Ak, 2018, s. 95). Andriç, Türklerin dış dünyaya, eşyaya yüklediği manevi anlamlara örnek olarak, eserde Drina Köprüsü’nü vermektedir. Eserde köprüye kutsiyet kazandırılmış, ona verilecek herhangi bir zararın günah olacağına inanılmaya başlanmıştır:

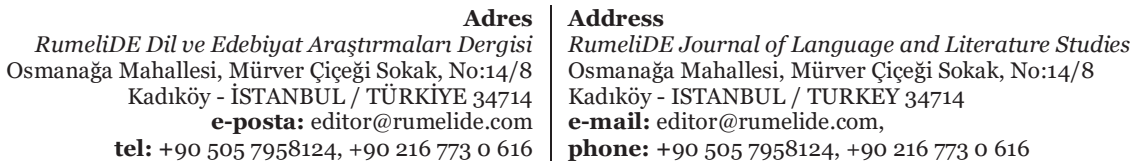


"Anladık... anladık... Hepsi güzel ama... Bunlar... Bu köprünün bir vezirin hayratı olduğunu bilmiyorlar mı?.. Onu Allah sevgisiyle ve ruhunun istirahati için yaptırmış olduğunu, onun bir taşını bile sökmenin günah olduğunu bilmiyorlar mı?” (s. 243).

“-Kardeşlerim! Bu köprü bir vezirin hayratıdır. Bu köprünün, gâvur kuvvetlere geçit vermediği yazılıdır. Onu biz değil ne kılıcın ne tüfeğin etkileyemeyeceği "bir evliya” koruyor.” (s. 128)

Köprüyle ilgili inanışlar, sadece bir evliyanın korumasından ibaret değildir. Köprünün gücünü artırmak için "köprü" kavramından başlayarak bir keramet oluşturulmuş; şeytan ile melekler arasındaki mücadelelere bile köprü dahil edilmiştir:

"Rahmetli babam, dünyada ilk köprünün nasıl kurulduğunu Şeyh Dede'den dinlemiș, bana çocukken anlatmıştı: Kadiri mutlak, dünyayı yarattığı zaman, dünyanın yüzü, nakışlı güzel bir tabak gibi dümdüz ve parlakmıs. Şeytan, Allah'ın Âdemoğluna bu bağıșını kıskanmıș ve henüz yeryüzü sertleşmemiş ve bir hamur gibi yumuşakken Allah'ın topraklarını uzun tırnaklarıyla kabil olduğu kadar derin tırmalamaya başlamıș... Hikâye rivayet eder ki, insanlarla ülkeleri birbirinden ayıran uçurumlar, ırmaklar böylece meydana gelmiş ve Allah'ın Âdemoğluna gıdasını sağlayacak bir bahçe gibi hediye ettiği dünyada onların bir yerden başka bir yere gitmelerini imkânsız bir hale sokmuş. Allah bu mel'unun yaptığı işleri görünce, gazaba gelmiş ama, şeytanın bozduğu bu işi baştan yapamayacağı için, insanlara yardım etmeleri ve her şeyi kolaylaştırmaları için meleklerini yollamış. Melekler zavallı insanların bu derinlikleri ve uçurumları aşamadıklarını, işlerini göremediklerini, bir kıyıdan öbür kıyıya seslenerek boşuna vakit kaybettiklerini görünce, bu yerlerin üstüne kanatlarını germișler, insanlar da bir yandan öbür yana kolayca geçebilmișler. Âdemoğlu da köprünün nasıl yapıldığını işte bu meleklerden öğrenmişler. Onun için köprü yaptırmak çeşme yaptırmaktan sonra en büyük sevaptır. Her köprünün ne biçim olursa olsun, ister bir selin üstüne uzatılan bir ağaç kütüğü, ister Mehmet Paşa'nın güzel eseri gibi olsun, başında daima bir melek bekler. Ve Cenabı Hak ona ne kadar ömür verdi ise o kadar dayanır" (s. 226).

Yazar, Türk kültürünün maddi unsurları arasında yer alan halı, kilim, seccade gibi eşyaları da eserine dahil etmiştir. İlginç olan, bu eşyaların Türkler tarafından değil, Türk olmayanlar tarafından kullanıllyor oluşudur. Bu durum, aynı topraklarda üzerinde yaşayan farklı milletlerin birbirlerinin kültürel ögelerinden yararlandıklarını da göstermektedir:

"Oraya geldiklerinde teğmen yardımcısı olan Salko Hedo, bir zaptiyenin yardımıyla Kapiya'nın basamaklarıyla Avusturyalı Albayın oturacağı taş sıranın üstüne parlak renkli Türk halısı sermiş bulunuyordu" (s. 132).

"Tam o sırada Rahip Nikola, üstüne bir Türk seccadesi serilmiş olan dar ve sert sedirin üstünde doğruldu” (s. 181).

Namus kavramı, birçok ülkede kadın ve erkekler için iyi ahlaklı olma, doğruluk, dürüstlük ve olumlu davranışlar olarak ele alınmaktadır. Yazar, Türklerin namuslarına olan hassasiyetini, bu uğurda gerekli gördüklerinde gözlerini kırpmadan bedel alabileceklerini Drina Köprüsü’nde işlenmiştir:

"Bu ülkede ve onun durumunda olan birinin bir Türk kızına yanaşmaya, dokunmaya cesaret etmesinin nasıl bir tehlike yaratacağını çok iyi biliyordu. Bunu orduda iken de şimdi Streifkorps'da da kendilerine söylemişlerdi. Bu gibi suçların cezası çok büyüktü. Gururları incinen öfkeli Türkler tarafından öldürülerek, bunu hayatları ile ödeyenler bile olmuştu” (s. 171).

Türklerde erkek çocuğun olmaması aile hayatını olumsuz yönde etkileyeceği gibi malların ve mülklerin dağllımını da olumlu ya da olumsuz yönde etkilemiş̧tir. Türklerin bozkır hayatında kızlardan ya da kadınlardan beklenen en önemli özellik, başlı başına doğurganlıktır. Çünkü Türklerde ailenin devamı çocuk ile kabildir, kadının öncelikli vazifesi bu hizmeti tam anlamıyla sunabilir olmasıdır (Karadoğan, 2019, s. 208, 209). Andriç, Hacı Ömer karakteri etrafında, Türk kültürünün önemli bir parçası olan, kişinin ilini, töresini yaşatması için çocuğunun olması gerekliliğine de yer vermiştir:

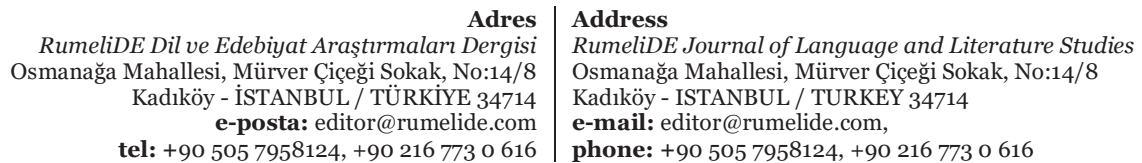

tel: $+905057958124,+902167730616$
Address

RumeliDE Journal of Language and Literature Studies

Kadıköy - ISTANBUL / TURKEY 3471

phone: +90 $5057958124,+902167730616$ 


\begin{abstract}
"Hacı Ömerler, her bakımdan kasabanın en iyi ve en itibarlı ailesiydi. Ama artık yaşlanmış olmalarına rağmen çocukları olmamıştı. Hacı Ömer, Kabe'ye gitmiş, karısı tekkelere, fakirlere bağışlarda bulunmuştu. Yıllar geçmiş, malları artmış, gelişmiş ama esas noktada Allanın lütfuna mazhar olamamışlardı. Hacı Ömer'le çok akıllı olan karısı bu mutsuzluğu sabır ve tevekkülle karşılamışlardı. Ama artık evlât sahibi olmak umudu da kalmamıştı. Kadın 45 yaşına gelmişti. Hacı Ömer'in arkasında bırakacağı zengin miras tehlikeye düşmüştü. Mesele sadece kalabalık olan akrabalarını değil, bütün kasabayı meşgul ediyordu. Akrabalar ciftin çocuksuz kalmasını diliyorlardı” (s. 209).
\end{abstract}

Göktürk Kitabelerinde yapılan uyarıların başında Çin’den geleceklere “...Çin milletinin sözü tatlı, ipek kumaşı yumuşak imiş. Tatlı sözle, yumuşak ipek kumaşla aldatıp, uzak milleti öylece yaklaştırırmış. Yaklaştırıp, konduktan sonra, kötü şeyleri o zaman düşünürmüş. İyi bilgili insanı, iyi cesur insanı yürütmezmiş. Bir insan yanılsa, kabilesi, milleti, akrabasına kadar barındırmazmış. Tatlı sözüne, yumuşak ipek kumaşına aldanıp çok çok, Türk milleti, öldün; Türk milleti öleceksin! ...” (Bilge Kağan Anıtı Güney Cephesi 5-6) şeklinde yapılan uyarıdır. Yabancıdan gelen her unsura karşı şüpheyle yaklaşılması gerektiği düşüncesi, eserde Ali Hoca’nın şahsında sergilenmiştir:

"Dükkânına kadar uzanan dumandan rahatsız olan Ali Hoca kaşlarını çatıyor ve dinsizlerin getirdikleri bu sudan küçümseyerek söz ediyordu. Onun düşüncesine göre bu su ne içmeye, ne de abdest almaya elverişliydi” (s. 228).

Yazar, Türklerin cihan hakimiyeti fikrinden, İslam dünyasındaki etkisinden de haberdardır. Türk egemenliği ile İslam inancının parçalanmaz bir bütün haline geldiğini vurgulamaktadır:

“Çocukluklarında Türk egemenliği, Lika'dan, Kordum'dan İstanbul'a kadar; İstanbul'dan da tâ o uzak ve erişilmez Arabistan'ın çöllerle kaplı belirsiz sınırlarına uzanıyordu. (Türk egemenliği demek... Muhammed dininin birleştirdiği yıkılmaz, parçalanmaz büyük bir topluluk demekti. Yeryüzünde müezzinlerin müminleri namaza çağırdıkları bütün yerleri içine alan topraklar demekti). (s. 250).

Andriç, eserde Türklerin yaşadığı sorunlara dair görüşlerini de dile getirmiştir. Yazara göre, Türklerin bilime dair eğiliminin olmaması veya Oryantalizm içinde Türklerin ele alınması, Osmanlı İmparatorluğu’nun Türk kültüründen bağlarını kopararak Arap kültürünü Türk dünyasına sokmasıyla olmuştur. İslamiyet’in kabulü Türklerin Arap kültürünü kabul edeceği anlamına gelmemektedir ve bu yüzden İslamiyet Türk dünyasında yeniden biçimlenmiştir. Fakat Osmanlı’nın İslamiyet’i Türk kültürü yorumundan uzaklaştırması, dünyada Türklerin Arap dairesinde görülmesine neden olmuştur. Kitapta yer alan aşağıdaki sözler de bu bakışı kanıtlar niteliktedir:

\begin{abstract}
"Bu çeşit sorunlarda sizler, bey oğulları, çŏ̆u zaman yanılıyorsunuz. Yeni, zamanlar düzeninizi bozduğu için dünyada artık kendinizi rahat hissetmiyorsunuz! Sizler, için doğu gelenekleri ve düșüncesi, yüzyıllarca egemenliğinizin temelini meydana getirmiș olan sosyal ve hukuk düzenine sıkıca bağlıdır. Bunu anlıyorum ama bu, Orientalisme’i bir bilim olarak kavradığınıza delil olamaz. Doğulusunuz. Kabul... Ama bunun için Orientalist olmak zorunda olduğunuzu sanıyorsanız yanılıyorsunuz. Genel olarak bilime istidadınız yok... Gerçek bir eğiliminiz de yok” (s. 265). ( “Hayır, yok... Bunu kesin olarak söylerken sizleri kıracak, fenanıza gidecek bir şey söylemiyorum. Tam tersine, bu toprakların biricik efendilerisiniz... Ya da daha doğrusu idiniz! Yüzylllar boyunca, egemenliğinizi genişlettiniz, güçlendirdiniz. Onu kâh kılıçla, kâh kitapla, dinî, hukukî ve askerî bakımdan savundunuz! Bu da sizi savaşçı, idareci, devlet adamı yaptı. Bu sinıfa giren insanlar dünyanın hiçbir yerinde soyut bilimlerle uğraşmazlar. Ekonomi, politika, hukuk öğrenimi sizin içindir. Çünkü sizler olumlu bilgiler için yaratılmış insanlarsınız. Egemen sınıfından olanlar her yerde ve her zaman böyledirler. - Yani kültürsüz kalmanız gerekiyor demektir. - Hayır, bu... ne iseniz o kalmanız gerekiyor demektir. Daha doğrusu ne idiyseniz demek gerek. Buna zorunlusunuz... Çünkü hiç kimse hem olduğu gibi kalıp hem de onun tersi olamaz" (s. 266).
\end{abstract}

Dile getirilen bu görüşler, bugün de süregelen, Batı dünyasının Türklerin sosyoloji, siyaset, felsefe gibi bilim dallarında yetkin olmadığı tezine dayanmaktadır. Fakat İslamiyet öncesi Türk devletlerinde Batı́nın yüzyıllar sonra keşfettiği sosyal devlet anlayışına rastlanır. Görünürde toplum bilimi olarak

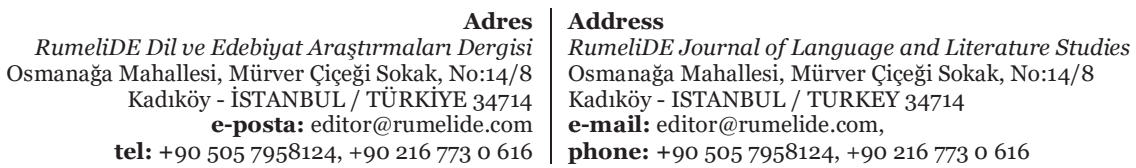


belirtilen fakat cephede savaşmadan bir halkı egemenliği altına almak için 19. yüzyılda bilimsel bir hale getirilen sosyolojinin birçok yöntem ve tekniğginin Orta Asya Türk devletleri ve Selçuklu döneminde birçok yöntem, teknik ve stratejisinin kullanıldığı görülür. Türklerin Batı'da bu gözle görülmesi yine aynı yola çıkar, Arap, Fars ve Bizans kültürü etkisinde kalıp kendi bağlarından kopan bir milletin başka kültürlerin olumsuzluklarıyla yaftalamasıdır. $\mathrm{Bu}$ durum, Çağatay (1996) tarafından da vurgulanmaktadır.

Andriç, eserde Türklere dair başka olumsuz yargılara da yer vermiştir. Bu yargılar genellikle çatışmaların anlatıldığı bölümlerde görülmektedir. Çünkü bu bölümlerde birbirine düşman en az iki grup vardır. Savaşın acımasızlı̆̆ı, geçmişte bir arada yaşamış bu toplumları, kin ve intikam hırsıyla doldurmuştur:

"Ufukta henüz yükselmemiş güneşin kızıllı̆̆ı altında, kulübenin bulunduğu yere askerlerle birkaç da silahlı kasabalı toplanmıştı. Bunlar, geceleyin kasabanın etrafında devriye gezerek askere yardım eden yerli Türklerdi” (s. 90).

"Kasabaya, mallarını mülklerini isyancıların yaktığı Müslüman aileleri göç etmişti. Etrafa kin ve intikam duyguları aşılıyorlardı" (s. 90).

"Bugünlerde hepsinin kalbi nefretle dolu idi. Öç alma duygusuyla tutuşuyordu. İstediklerini öldürmedikleri için ellerine geçeni öldürmek istiyorlardı. Komutan onları anlamıyor, onlara hak vermiyordu. Ama karakolun, daha ilk günü birini yakalamasını istediklerini anlıyordu. İsteklerine karşı gelecek olursa onları kızdıracaktı. Zararı da kendisine dokunacaktı. Bu kaçık ihtiyar yüzünden başının derde girmesi ihtimali ona çok fena geldi.” (s. 93).

"O günden başlayarak isyancılarla ilgisi olan ya da olduğundan şüphe edilenler, ister sınırda, ister köprüde yakalansın, muhakkak sorguya çekiliyor ve içlerinden pek azı sağ kalıyordu. İsyancıların ya da mutsuzların başı burada kesiliyor ve karakolun etrafına çakılmış kazıklar üstünde gösteriliyordu. Ölülerini gelip arayan olmazsa Drina’ya firlatıyorlardı” (s. 97).

"Burada oturmuş, gülüp eğleniyorsunuz ama, Stanşevats'da neler olduğunun farkında bile değilsiniz. İşte biz, Türk topraklarına göç ettik. Ama, sizler, sıranız gelince acaba nereye gideceksiniz? Bunu kimse bilmez... Hiçbiriniz de düşünmüyorsunuz” (s. 105).

Savaşın toplumlar arasındaki uçurumu artırması, yorgunluk ve yılgınlığı da beraberinde getirmiştir. Sonuçta savaşın kaybedeni herkes olmuştur:

Zaman içinde savaş toplumları "Yerli Müslümanlar bile oradan geçerken artık zevk duymuyorlardı. Sırplara gelince; zorunluk duymadıkça geçmiyor, geçtikleri zaman da gözlerini kaldırmadan acele acele yürüyorlardı" (s. 98).

"Kapiya'da konuşulan şeylerin üstünden de 30 yıla yakın bir zaman geçti. Rüyan serdarı ile Türk delegesinin sınır boyunca diktikleri direkler, kökleşmişti. Biraz geç gelişmişti ama Türklere acı meyvelerini vermeye başlamıştı bile... Türkler, Sırbistan'daki en son şehirlerini de bırakmak zorunda kaldılar" (s. 102).

Eserde, yukarıdaki örneklerin dışında Türk kültürüne, Türk tipine örnek teşkil eden pek çok benzer örnek yer almaktadır. Örneklerin fazlalığı, Drina Köprüsü’nde Türk varlığının yoğunluğunu gösterir niteliktedir.

\section{Sonuç}

Eserlerinin birçoğu Osmanlı İmparatorluğu ve Türklerle ilgili olan İvo Andriç’in Nobel ödülü almasında önemli rolü olduğu kabul edilen Drina Köprüsü adlı eseri özelinde yapılan bu çalışma, bir edebiyat ürününün her bir katmanından farklı okumalarla birçok malzeme çıarılabileceğini ortaya koymaktadır. Drina Köprüsü’nün çok uluslu bir yapı içinde kaleme alınmış olması, eseri kültürel unsurlar açısından zenginleştirmiş, eserin bu yönüyle ele alınmasını kolaylaştırmıştır. Çünkü eser, hem tarihsel açıdan

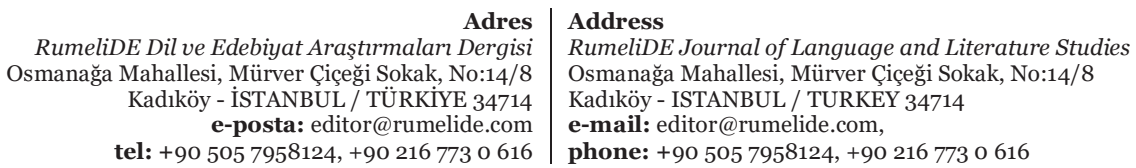


yüzlerce yıllık bir birikime sahiptir hem de içeriğinde yer alan insanlar farklı dil, din, ırk gibi özellikleri taşımaktadır.

Çalışma, eserde gelişen olaylardan çok, kültürel unsurların, tipolojik özelliklerin tespitini amaçlamıştır. Bu bağlamda eser, farklı çalışmalar ışı̆̆ında defalarca okunarak, eserde Türk kültürü ve kimliğine dair ipuçları tespit edilmeye çalışılmış, elde edilen bulgular gruplandırılarak ayıklanmış, tekrarlanan örneklerden seçmeler yapılmıştır.

Drina Köprüsü’nde Türklere dair, Roux (1991, s. 19) tarafından sıralanan "maddi ve manevi sağlamlı", "onura verilen önem", "verilen söze sadık kalmak", "ihanet edenlere karşı acımasızllk", "rrkçılığın olmaması". "Askeri toplumsal örgütlenmenin doğurduğu; gözü peklik", "kendisinin ve başkalarının hayatını hiçe saymak", "savaşanlar arasında dayanışma" ve "üste kesin itaat" gibi özelliklerin birçoğunun yer aldığı görülmüştür.

Vatanı için, namusu için gözünü kırpmadan savaşma ama barış yollarını, bir arada huzur içinde yaşama ilkesini görmezden gelmeme, eserde yer alan tip özelliklerindendir.

Doğruluk, dürüstlük, dostluk, uyanık olma, hileye, yolsuzluğa firsat vermeme gibi tipolojik özellikler de eserde dikkat çekmektedir.

Türk din adamları arasından hem olumlu hem olumsuz örneklere yer verildiği, Türklerin birtakım batıl inanışlarının, efsaneler ve evliyalara inanışlarının da eserde yer aldığı̆ görülmektedir.

Türk kültürünün temel zanaatlarından olan dokumacllı ürünlerinden halı, kilim, seccade gibi ürünler de Drina Köprüsü’nde yer alan kültürel unsurlar arasında yer almaktadır.

Drina Köprüsü’nde Türklere dair olumsuz değerlendirmelere de rastlanmaktadır. Türkler, bilime mesafeli olmakla, yllgınlıkla itham edilirken, bu durumun bir kader olduğu iddia edilmektedir.

Çalışma, farklı kültürlerin bir arada yaşama kararlılıklarını, etkileşimlerini, çatışmalarını, düşmanlıklarını ortaya koyması açısından da ilginç verilere sahip olup bu yönüyle yeni araştırmalara da katkı sağlar niteliktedir.

\section{Kaynakça}

Ak, M. (2018). Türk Halk Dindarlığı ve Evliya İnancı: Sosyolojik Bir Yaklaşım. Türk Kültürü ve Hacı Bektaş Veli Araştırma Dergisi. 86, 95-110.

Akgündüz, A. (1999). Bilinmeyen Osmanl. İstanbul: Osmanlı Araştırmaları Vakfı.

Andriç, İ. (2008). Drina Köprüsü. (Çev. Hasan Âli Ediz, Nuriye Müstakimoğlu). İstanbul: İletişim Yayınları.

Çağatay, N. (1996). Türklerin Tarihteki Yeri ve Millî Özellikleri. Erdem. 23, 503-528

Demir, A. (2017). Osmanlı Devleti'nde Devşirme Sistemi. Uluslararası Sosyal Bilimler Dergisi. 1 (1), 1927.

Demir, M. (2016). İvo Andriç̧in Drina Köprüsü Adlı Romanında Osmanlı Algısına Genel Bir Bakış. Avrasya Etüdleri. 50 (2), 453-470

Erkal, M. (2012). Sosyoloji (Toplumbilimi). İstanbul: Der Yayınları.

Gökalp, Z. (1991). Türk Uygarlk Tarihi. İstanbul: İnkılap Kitabevi.

Gökalp, Z. (1969). Türkçülüğün Esasları. İstanbul: Milli Hareket Yayınları.

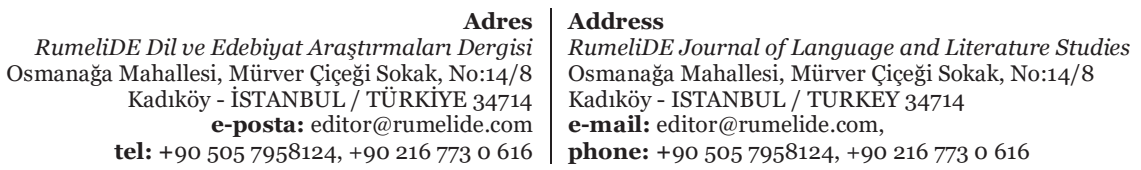


Güney, S. (2019). Davranış Bilimleri. Ankara: Nobel Akademik Yayıncllı.

Güvenç, B. (1979). İnsan ve Kültür. İstanbul: Remzi Kitabevi.

İnalcık, H. (2009). Devlet-i Alliye Osmanl İmparatorluğu Üzerine Araştırmalar-I. İstanbul: Türkiye İş Bankası Kültür Yayınları.

İnan, A. (2007). Atatürk Hakkında Hattralar ve Belgeler. İstanbul: Türkiye İş Bankası Kültür Yayınları. Kafesoğlu, İ. (2021). Milli Kültürümüz. Ötüken Yayınları: İstanbul

Kaplan, M. (1991). Türk Edebiyatı Üzerinde Araştırmalar 3: Tip Tahlilleri. 2. Baskı, İstanbul: Dergâh Yayınları.

Kara, Ü. (2014). Türk Destan Kahramanı ve Başkurt Destanlarının Tipolojisi. Konya: Kömen Yayınları.

Karadoğan, U. C. (2019). "Çocuk ve Çocukluk” Kavramının Tarihsel Süreçte Değerlendirilmesi. Çocuk ve Medeniyet. 4 (7) , 195-226.

Kolcu, A. (2003). İvo Andriç ve Drina Köprüsü Romanı. Türklük Bilimi Araştırmaları. 14, 219-245

Meriç, C. (2017). Kültürrden İrfana. İstanbul: İletişim Yayınları.

Ögel, B. (1948). Çin Kaynaklarına Göre Wu-Sun'lar ve Siyasî Sınırları Hakkında Bazı Problemler. Ankara Üniversitesi Dil ve Tarih, Coğrafya Fakültesi Dergisi. 6 (4), 259-278

Grousset, R. (2019) Bozkırın İmparatorluğu, Atilla-Cengiz Han-Timur. İstanbul: Ötüken Yayınları.

Roux, J. P. (1991). Türklerin tarihi, Büyük Okyanus'tan Akdeniz’e iki bin yıl. (3. Baskı). (Üstün, G. Çev.). İstanbul: Milliyet Yayınları.

Roux, J. P. (2002). Türklerin ve Moğollarm Eski Dini. İstanbul: Kabalcı Yayınevi.

Sarıtaş, S. (2019). Halk Biliminde Maddi Kültüre Teorik ve Metodolojik Yaklaşımlar. Milli Folklor Dergisi. 122, 29-40

Soysal, M. (1969). 100 Soruda Anayasanın Anlamı. İstanbul: Gerçek Yayınevi.

Sümer, F. (1972). Oğuzlar (Türkmenler) Tarihleri-Boy-Teşkilâtı-Destanları. Ankara: Ankara Üniversitesi Basımevi.

Şimşek, Ş. ve diğerleri. (2011). Davranış Bilimleri Giriş ve Örgütlerde Davranış. Ankara: Gazi Kitabevi.

Tezcan, M. (2015). Sosyolojizye Giriş. Ankara: Anı Yayınları.

Tylor, E. B. (1871). Kültür Bilimi, (Çeviri: Esra Dabağcl) ViraVerita E-Dergi. 4, 91-109

Ziya Gökalp Özel Sayısı (2019). Millî Mecmua Dergisi, 6

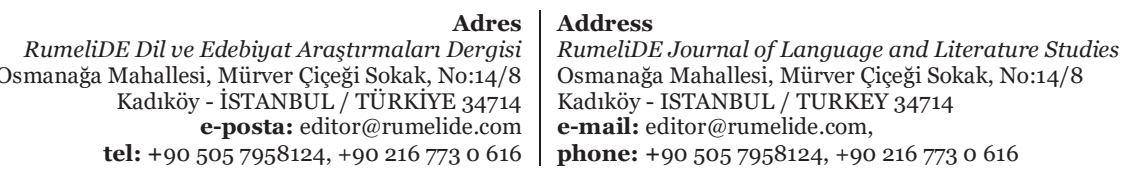

